justifies the determination of Shumway's group to pursue research in human cardiac tramsplantation. The lessons seem to be clear. The early mortality is high, but these patients were in preterminal heart failure, and a similar mortality figure was reported not long ago for triple valve replacement. 10 We can expect to achieve better control of the immunological problems in future and thus lower the early heavy losses from acute rejection (too little suppression) or from infection (which is often the sequel of too much). Only when these hazards have receded will it be justifiable to operate on patients before they reach the stage of failure of all organs from inadequate perfusion. Then, as with valve replacements, the operation mortality will fall substantially.

Suitable candidates for cardiac transplantation at present are patients with permanent incapacity due either to ischaemic damage or to cardiomyopathy. Moderate pulmonary hypertension is reversible, but severe pulmonary vascular disease may pose too severe a burden on the donor right ventricle. Infants and young people with complex congenital cardiac defects should not be subjected to this operation until the donated heart is known to have a reasonably long expectation of survival and function.

The excellent performance of Shumway's patients after a year and the relatively low later mortality in his survivors are tremendously encouraging. The report from his pioneer group gives hope that cardiac transplantation may yet be more generally undertaken in the major cardiac centres and so provide real palliation in myocardial disease.

\footnotetext{
1 Shumway, N. E., Angell, W. W., and Wuerflein, R. D., Transplantation, $1967,5,900$.

2 Barnard, C. N., American fournal of Cardiology, 1968, 22, 584

Dempster, W. J., Melrose, D. G., and Bentall, H. H., British Medical Fournal, 1967, 1, 177

Goodwin, J. F., and Oakley, C. M., American Heart Fournal, 1969, 77,

437.
Cooley, D. A., Bloodwell, R. D., Hallman, G. L., and Nora, J. J., fournal of the American Medical Association, 1968, 205, 479.

Griepp, R. B., Stinson, E. B., Dong, E., Clark, D. A., and Shumway, N. E., Surgerv, 1971, 70, 88.

T. E., Surgery, 1971, 70, 88.

Botha, M. C., South African Medical fournal

- Donald, D. E., Circulation, 1968, 38, 225. tion, 1967, 35, 96.

10 Kittle, C. F., et al., Circulation, 1969, 39, 169.
}

\section{Compression of Coeliac Axis}

Reports continue to appear on the coeliac axis compression syndrome. Abdominal pain is said to be provoked by partial occlusion of the coeliac axis. There are now some 80 well-documented cases, and the latest paper, from Canada, ${ }^{1}$ is unique in that not only symptoms but gross organic changes are attributed to ischaemia from coeliac axis stenosis. Do all these cases exemplify a real syndrome?

It was first described by J. D. Dunbar and his colleagues ${ }^{2}$ from Columbus, Ohio, in 1965, when 15 cases were presented. This group has the largest reported series to its credit with 30 cases. $^{3}$ If these cases all represent the same syndrome, it has the following features. Eighty-one per cent. are women, and though some reports stress youth as an important criterion ${ }^{34}$ the average age is 43 years; two series show mean ages of $51^{5}$ and 52.6 Symptoms are of upper abdominal pain and bloating immediately after food, ${ }^{4}$ and in others the pain is said to be continuous. ${ }^{1}$
Loss of weight and diarrhoea-two cardinal symptoms of mesenteric ischaemia-are not specially notable and were respectively present in $35 \%$ and $42 \%$ of all reported cases. The patients tended to be leptosomatic and asthenic, but the only abnormal physical sign was an upper epigastric non-radiating bruit. ${ }^{34}$ The diagnosis is established by biplanar angiography, in which the lateral aortogram shows extrinsic anterior narrowing of the coeliac axis with poststenotic dilatation. Enlargement of the pancreatico-duodenal arteries as collaterals between coeliac and superior mesenteric vessels is seen on the anteroposterior films. Selective catheterization of the coeliac axis is impossible, but a superior mesenteric angiogram fills the coeliac axis via collaterals and flow is delayed through its branches. ${ }^{24}$ No other investigation appears to help diagnosis. ${ }^{3}$

But there are obstacles to accepting the validity of the syndrome. The symptoms attributed to it are rather vague and highly subjective, and in some cases the patients have had psychiatric care. ${ }^{19}$ The significance of the only physical sign-the bruit-is not great, ${ }^{4} 10$ and the $x$-ray appearances may be incidental, since they may be seen in asymptomatic people. ${ }^{1911}$ Objective measurement is difficult or impossible.

The factors concerned in visceral ischaemia are comolex. The blood supply to the gut must be rich enough to sustain the high cellular turnover of the intestinal mucosa and in addition carry sufficient reserve to meet the enormous requirements of digestion. Moreover, the visceral circulation is peculiarly dependent on an adequate arterial inflow, for it has to contend with the raised venous outflow pressure of the portal tract and yet is devoid of barorecentors necessary for local protective vasomotor reflexes. ${ }^{12}$ However, there is a huge collateral potential between the three maior arteries to the gut-namely, coeliac and the superior and inferior mesenteric. In favourable circumstances any one artery can take over the distributive fields of the others. The extent of this capacity was first shown in 186913 in a postmortem study but has been confirmed surgically since. ${ }^{14}$ Indeed L. H. Appleby ${ }^{15}$ has advocated ligature of the coeliac axis for the treatment of stomach cancer and reported 13 cases without any apparent ischaemic problems. It has usually been maintained that two out of three of the visceral arteries have to be occluded before ischaemia of the gut is produced, ${ }^{16-18}$ lesser degrees of obstruction being insignificant. J. R. Derrick and colleagues ${ }^{19}$ found narrowing of the coeliac axis in $44 \%$ of unselected necropsy cases. From angiographic studies A. P. Dick and his co-workers ${ }^{20}$ calculated that the total cross-sectional area of the three arteries to the gut had to be reduced below two-thirds before ischaemia was produced. This sort of evidence has to be discarded if partial occlusion of the coeliac axis is accepted as giving rise to symptomatic ischaemia. However, A. J. Edwards and colleagues ${ }^{4}$ showed that a "steal" or an intermittent hyperaemic flow pattern could occur in a manner that would allow the symptoms to be vascularly determined without negating the above evidence, though they did not favour this hypothesis. In their hands the restoration of the flow pattern to normal was not always accompanied by loss of symptoms. It would seem most unlikely that isolated narrowing of the coeliac artery could, as has been claimed, cause gastric fibrosis, haemorrhagic gastritis, pancreatic insufficiency, ${ }^{1}$ or hepatic cirrhosis. ${ }^{21}$ The coincidence of organic disease and narrowing of the coelic axis does not prove the disease to be due to the constriction and at the same time it prompts the suggestion that the symptom may not be due to the arterial deformity at all. 
Despite the ample collateral circulation treatment has been directed towards the operative relief of the coeliac stenosis. Most authors ${ }^{134}$ consider that removal of the compressive agent is adequate, but $R$. S. A. Lord and colleagues $^{5}$ think that the artery is so damaged as to make its excision and reconstruction mandatory. Others ${ }^{1} 4$ have angiographic proof that residual stenosis will resolve after the compressive agent has been removed and are therefore opposed to this extreme view.

Disagreement exists on whether compression is due to the median arcuate ligament of the diaphragm ${ }^{3}$ or fibrosis in the coeliac plexus or ganglion. ${ }^{6-8}$ This is an important distinction, for it allows explanation of the syndrome either on rheological or on neurological grounds. Possibly the coeliac nervous plexus give rises to, or transmits, the pain, and the success of the operation depends more on neurectomy than arterial decompression. ${ }^{4} 8$ The success of surgical treatment varies in the different reports, ranging from $100 \%^{18}$ to $40 \% .4$ If the 72 cases whose follow-up has been reported may be considered as one group, then $79 \%$ were rendered asymptomatic, $11 \%$ improved, and $10 \%$ unaltered by operation. For the 53 cases from North America alone the figures are $88 \%, 8 \%$, and $4 \%$, while those from Europe are $63 \%, 16 \%$, and $21 \%$.

Such therefore are the difficulties in understanding the coeliac axis compression syndrome that its existence and definition ought still to be considered sub judice, and patients should be exposed to the risks of angiography and surgical treatment only after the utmost circumspection. In the meantime every opportunity should be taken to document the visceral circulation in health and disease to improve our understanding of the role of ischaemia as a cause of gastroenterological symptoms.

${ }^{1}$ Charrette, E. P., Iyengar, S. R. K., Lynn, R. B., Paloschi, G. B., and West, R. O., Surgery, Gynecology and Obstetrics, 1971, 132, 1009.

Dunbar, J. D., Molnar, W., Beman, F. F., and Marable, S. A., American Fournal of Roentgenology, 1965, 95, 731.

Marable, S. A., Molnar, W., and Beman, F. M., American fournal of Surgery, 1966, 111, 493.

Edwards, A. J., Hamilton, J. D., Nichol, W. D., Taylor, G. W., and Dawson, A. M., British Medical fournal, 1970, 1, 342.

5 Lord, R. S. A., Stoney, R. J., and Wylie, E. J., Lancet, 1968, 2, 795

- Harjola, P. T., and Lahtiharju, A., American fournal of Surgery, 1968, 115,864 .

${ }^{7}$ Harjola, P. T., Annales Chirurgiae et Gynaecologiae Fenniae, 1963, 52, 547

Snyder, M. A., Mahoney, E. B., and Rob, C. G., Surgery, 1967, 61, 372

- Drapanas, T., and Bron, K. M., Annals of Surgery, 1966, 164, 1085.

Julius, S., and Stewart, B. H., New England fournal of Medicine, 1967, 276, 1175.

11 Reuter, S. R., and Olin, T., Radiology, 1965, 85, 617.

12 Edwards, A., St. Bartholomew's Hospital fournal, 1970, 78, 161.

13 Chiene, J., Fournal of Anatomy, 1869, 3, 65.

14 Rob, C. G., and Owen, K., British Fournal of Surgery, 1956, 44, 247.

15 Appleby, L. H., Cancer, 1953, 6, 704.

16 Mikkelsen, W. P., American fournal of Surgery, 1957, 94, 262.

17 Morris, G. C., and DeBakey, M. E., Fournal of the American Medical Association, 1961, 176, 89.

Association, 1961, 176, 89.
18 Rob, C. G., Archives of Surgery, 1966, 93, 21. 19 Derrick, J.' R., Pollard, H. S., and Moore, R. M., Annals of Surgery,

${ }^{20}$ Dick, A. P., Graff, R., Gregg, D. McC., Peters, N., and Sarner, M., Gut, $1967,8,206$.

21 Deutsch, V., Clinical Radiology, 1968, 19, 309.

\section{Felty's Syndrome}

In 1924 A. R. Felty, ${ }^{1}$ an American physician, described five cases of chronic rheumatoid arthritis with splenomegaly and neutropenia. Most of the patients were anaemic, and enlargement of the lymph nodes, loss of weight, remittent fever, and brown pigmentation of the skin were noted. Later other findings were added-ulceration of the shins and thrombocytopenia.
All these are features of classical rheumatoid arthritis, some commonly (anaemia, lymphadenopathy, remittent fever, and loss of weight), others more rarely (neutropenia and splenomegaly). Most rheumatologists have considered the condition to be merely an uncommon variant of rheumatoid disease in which, for some unknown reason, hypersplenism occurs. In a few instances cirrhosis of the liver occurs. In the majority of cases the only apparent cause for the splenomegaly is rheumatoid arthritis. Females predominate and the patients are usually over 45 years of age. The rheumatoid disease is usually advanced and severe and strongly seropositive. Antinuclear factors are often present in high titres, and an antinuclear factor reacting specifically with nuclei of polymorphonuclear leucocytes occasionally appears. $^{2}$

The importance of the condition lies in the dangers to health and to life from intercurrent infection, as neutrophil response to infection is impaired. Rheumatoid arthritics are notoriously prone to infective complications even without neutropenia. With neutropenia the risk is considerably increased and the danger to life greater. Ulcers of the shin and lower leg are commoner than in simple rheumatoid arthritis and usually more troublesome.

Recently C. G. Barnes, A. L. Turnbull, and B. VernonRoberts $^{3}$ have made a fresh study of Felty's syndrome at the London Hospital and have surveyed 21 patients, 6 males and 15 females, with this disorder. The males progressed to Felty's syndrome more rapidly than the females ( 1 to 10 years with a mean of six years in males as compared with 3 to 34 with a mean of $\mathbf{1 4 . 2}$ years in females). At the time of diagnosis of Felty's syndrome the rheumatoid disease was active in nine, quiescent in eight, and comparatively inactive in four. Rheumatoid nodules were present in all but six patients, three men and three women. Eleven patients were considered to have Sjögren's syndrome, as indicated by an abnormal Schirmer's test. Test for rheumatoid factor were positive in 19 patients and consistently negative in two. Either antinuclear factor tests or L.E. cell preparations were positive at some time in 14 of the 21 patients reviewed and white cell antinuclear-factor tests were positive in 6 of 10 patients tested. The spleen was palpable in all but two patients, one of whom was grossly obese. A mild increase in skin pigmentation was noted in only three and ulceration of the legs in four patients. All patients were anaemic, but only three had less than $8 \mathrm{~g} / 100 \mathrm{ml}$ haemoglobin. Thrombocytopenia (less than $150,000 / \mathrm{mm}^{3}$ ) was present in 10 patients. Ten patients underwent splenectomy and were

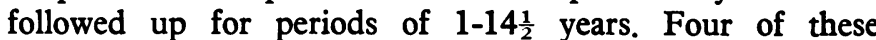
patients died after operation, two were cured, and two achieved normal blood counts after early relapses. In eight of the 10 patients there was an immediate improvement, but this was maintained in only two followed up now for $14 \frac{1}{2}$ and six years; four of the 11 patients who did not undergo operation died in the follow-up period. In spite of these rather undramatic postoperative results the authors consider splenectomy the treatment of choice in patients, firstly, with very severe infection; secondly, with severe anaemia due to sequestration of red cells and haemodilution or to haemolysis which cannot be controlled by small doses of corticosteroids; and, thirdly, severe haemorrhage associated with thrombocytopenia. ${ }^{4}$

A recent paper ${ }^{5}$ from Charlottesville, Virginia, reports 15 patients with Felty's syndrome followed up for 1 to $13 \frac{1}{2}$ years after splenectomy. The operation relieved the neutropenia in $66 \%$ of the patients, with no late relapses. The frequency of infections was much decreased in most of the 